\title{
Downregulation of EphA1 in colorectal carcinomas correlates with invasion and metastasis
}

\author{
Yingchun Dong ${ }^{1,5}$, Jiandong Wang ${ }^{1,2,5}$, Zhen Sheng ${ }^{1}$, Guoli $\mathrm{Li}^{3}$, Henghui Ma ${ }^{1}$, Xulin Wang ${ }^{3}$, \\ Rusong Zhang ${ }^{1}$, Guangming $\mathrm{Lu}^{2}$, Qiuju $\mathrm{Hu}^{2}$, Haruhiko Sugimura ${ }^{4}$ and Xiaojun Zhou ${ }^{1}$ \\ ${ }^{1}$ Department of Pathology, Clinical School of Medical College of Nanjing University, Nanjing Jinling Hospital, \\ Nanjing, PR China; ${ }^{2}$ Department of Radiology, The Center for Molecular Imaging Research, Jinling Hospital, \\ Nanjing University, Nanjing, PR China; ${ }^{3}$ Department of Surgery, Jinling Hospital, Nanjing University, \\ Nanjing, PR China and ${ }^{4}$ Department of Pathology, Hamamatsu University School of Medicine, Hamamatsu, \\ Japan
}

The Eph gene family has important roles in the developmental processes and may also be involved in the initiation, progression, and metastasis of certain types of cancers. In the present study, quantitative real-time reverse-transcriptase PCR was performed to detect the expression of EphA1 transcript in 5 colon cancer cell lines and 75 colorectal carcinomas. Immunohistochemical staining was used to check the expression of EphA1 protein in 20 colorectal adenomas and in 111 colorectal carcinomas specimens. EphA1 protein expression was not completely consistent with transcript expression. EphA1 protein was expressed in all adenomas and reduced in $54 \%$ colorectal cancers. Reduced expression of EphA1 protein occurred more often in male patients $(P=0.028)$ and in patients with poor differentiation $(P=0.027)$, greater depth of wall invasion $(P=0.003)$, lymph node metastasis $(P=0.034)$, and advanced tumor stage $(P=0.003)$. Patients with reduced EphA1 expression had a poor overall survival $(P=0.059)$. Reduced EphA1 expression in patients over 55 years or with rectal cancers and sigmoid colon cancers is associated with a poor overall survival $(P=0.034$ and 0.015 , respectively). Our data indicate that the EphA1 may play different roles during the different stages of colorectal carcinoma progression.

Modern Pathology (2009) 22, 151-160; doi:10.1038/modpathol.2008.188; published online 14 November 2008

Keywords: EphA1; colorectal carcinoma; invasion; metastasis; survival

Colorectal carcinoma is one of the most common malignant tumors. There are estimated 112340 new cases of colon cancer and 41420 new cases of rectum cancer in USA, and estimated 52180 cases of colorectal cancer patients died in 2007. The incidence and mortality rate of colorectal cancer rank the third in all types of cancers both of male and female patients. ${ }^{1}$ The search for new molecular targets of early diagnosis, rational therapy, and prognosis is the current research hot spot.

Eph receptors, the largest subfamily of the receptor tyrosine kinases, are divided into two subfamilies, EphA and EphB, based on the sequence

Correspondence: Professor X Zhou, MD, PhD, Department of Pathology, Nanjing Jinling hospital, Clinical School of Medical College of Nanjing University, Nanjing 210002, PR China and Professor G Lu, Department of Radiology, The Center for Molecular Imaging Research, Jinling Hospital, Nanjing University, Nanjing, PR China.

E-mails: nanjing_81@yahoo.com and cjr.luguangming@vip.163.com

${ }^{5}$ These authors contributed equally to this work.

Received 13 May 2008; revised and accepted 23 June 2008; published online 14 November 2008 homology of their extracellular domains and their affinity to bind corresponding ligands, EphrinA and EphrinB (Eph Nomenclature Committee, 1997). ${ }^{2}$ The Eph family of receptor tyrosine kinases has important roles in diverse biological processes including nervous system development, ${ }^{3-5}$ angiogenesis, ${ }^{6}$ and vascular system development. ${ }^{7}$ A number of Eph receptors and their ephrins ligands are implicated in carcinogenesis. ${ }^{8-16}$ EphA1, the first member of Eph receptors tyrosine kinase, was isolated from erythropoietin-producing hepatocellular carcinoma cell lines and is located on chromosome $7 \mathrm{q} 34 .{ }^{17}$ It is widely expressed in normal tissues including lung, small intestinal, kidney, bladder, thymus, and colon. ${ }^{18}$ The expression level of EphA1 in human cancers is variable. Overexpression of EphA1 was observed in certain types of tumors including ovarian carcinoma, ${ }^{19}$ and head and neck squamous carcinoma. ${ }^{20}$ Reduced expression of EphA1 was detected in prostate cancer cell lines, ${ }^{21}$ breast carcinoma cell lines, ${ }^{12}$ and basal-cell carcinomas and squamous-cell carcinoma specimens of the skin. ${ }^{22}$ There was a marginal study of EphA1 
expression in colorectal carcinoma specimens, particularly, with respect to clinicopathologic parameters. In this study, we performed quantitative real-time reverse-transcriptase PCR (RT-PCR) and immunohistochemistry to detect the expression of EphA1 mRNA and protein in a set of colorectal carcinomas and adenomas. And the association of EphA1 expression levels with clinicopathologic parameters of colorectal carcinomas was analyzed. To our knowledge, this is the first description of the role of EphA1 in colorectal progression and prognosis.

\section{Materials and methods}

Five colon cancer cell lines DLD1, HCT116, HT29, SW480, and SW620 were used in the present study. The cells were routinely cultured in Dulbecco's modified Eagle's medium (NISSUI Pharmaceutical Co., Tokyo, Japan), supplemented with $1 \mathrm{mmol} / \mathrm{l}$ L-glutamine, $10 \%$ fetal bovine serum (FBS; Life Technologies Inc.), and antibiotics $(100 \mathrm{U} / \mathrm{ml}$ of penicillin $\mathrm{G}$ and $100 \mu \mathrm{g} / \mathrm{ml}$ of streptomycin). The cells were incubated at $37^{\circ} \mathrm{C}$ in a humidified atmosphere of $95 \%$ air and $5 \% \mathrm{CO}_{2}$.

All the tissue samples in our study were collected from 111 patients with colorectal carcinoma and 20 patients with colorectal adenomas, as part of a study approved by the Research Ethics Board of the Nanjing Jinling Hospital, Clinical School of Medical College of Nanjing University. These patients had undergone surgery in Nanjing Jinling Hospital between 2004 and 2006 without any preoperative therapy. Among the 111 cases of colorectal carcinomas, 75 fresh tissue samples including cancer tissues and matched normal mucosas were immediately frozen in liquid nitrogen after the resection and then stored at $-80^{\circ} \mathrm{C}$ for the preparation of the total RNA. Formalin-fixed and paraffin-embedded tumor tissues were sectioned at $4 \mu \mathrm{m}$ thickness and stained with hematoxylin and eosin for the pathological identification. The patients included 66 men and 45 women. Ages ranged from 23 to 84 (median age: 59 years). The distribution of the tumors by sites of origin was as follows: the cecum and ascending colon, 26 tumors; the transverse colon, 4 tumors; the sigmoid colon, 14 tumors; and the rectum, 67 tumors. The clinicopathologic variables of the 111 patients of colorectal carcinoma were shown in Table 1. The tumor stage was classified according to the TNM classification of World Health Organization of 2007.

\section{Quantitative Real-Time RT-PCR}

The total RNA was extracted using the RNA extraction reagent TRIzol (Invitrogen, CA, USA) according to the manufacturer's protocol. Single-strand cDNA was synthesized using $2 \mu \mathrm{g}$ total RNA with an oligo(dT) primer. Quantitative real-time RT-PCR was performed to detect the EphA1 transcript expression in colorectal carcinoma on an ABI Prism 7000 Sequence Detection System (Applied Biosystems, Foster City, USA). The experiments were run in triplicate. The sense primer, antisense primer, and TaqMan probe for detection of EphA1 were designed according to the EphA1 mRNA sequence (GenBank accession number: NM_005232). The sense primer is $5^{\prime}$-ATCTTTGGGCTGCTGCTTGG- $3^{\prime}$ and the antisense primer is $5^{\prime}$-GCTTGTCCTCTCGATCCACA TC- $3^{\prime}$. The PCR products are $127 \mathrm{bp}$ long. The TaqMan probe is $5^{\prime}$-(FAM) CGGTCACGCTGC CTCTGCTGCC (Eclipse)-3'. The housekeeping gene glyceraldehyde-3-phosphate dehydrogenase $(G A P D H)$ was used as an internal control (GenBank accession number: NM_002046). The sense primer is $5^{\prime}$-CCAGGTGGTCTCCTCTGACTT- ${ }^{\prime}$ and the antisense primer is $5^{\prime}$-GTTGCTGTAGCCAAATTCGTT GT- $3^{\prime}$. The PCR products are $130 \mathrm{bp}$ long. The probe is $5^{\prime}$-(FAM) AACAGCGACACCCACTCCTCCACC (Eclipse)-3'. The values of EphA1 mRNA expression were normalized using the GAPDH expression. The primers and probes for EphA1 and GAPDH were synthesized by TaKaRa Biotechnology Inc. (Dalian, China).

The reaction mixture consisted of $3.0 \mu \mathrm{l} 10 \times$ buffer; $3.0 \mu \mathrm{l} 2.0 \mu \mathrm{mol} / \mathrm{l}$ deoxy-ribonucleoside triphosphates (dNTPs; Invitrogen); $3.0 \mu \mathrm{l} 3.0 \mu \mathrm{mol} / \mathrm{l}$ sense primer; $3.0 \mu \mathrm{l} 3.0 \mu \mathrm{mol} / \mathrm{l}$ antisense primer; $1.0 \mu \mathrm{l}$ $3.0 \mu \mathrm{mol} / \mathrm{l}$ fluorescence probe; $0.20 \mu \mathrm{l} 5 \mathrm{U} / \mu \mathrm{l}$ Takara ExTaq Hotstart Taq (TaKaRa Biotechnology), $0.6 \mu \mathrm{M}$ 5-carboxy-X-rhodamine reference dye (Invitrogen), $2.0 \mu \mathrm{l}$ cDNA template, and distilled water for a total volume of $30 \mu \mathrm{l}$. The PCR cycling conditions were used as follows: $2 \mathrm{~min}$ at $95^{\circ} \mathrm{C}$, followed by 40 amplification cycles of denaturation at $94^{\circ} \mathrm{C}$ for $30 \mathrm{~s}$, annealing at $59^{\circ} \mathrm{C}$ for $30 \mathrm{~s}$, and elongation at $72^{\circ} \mathrm{C}$ for $1 \mathrm{~min}$.

\section{Immunohistochemistry}

Formalin-fixed, paraffin-embedded samples used for immunohistochemistry were sectioned at $2 \mu \mathrm{m}$ thickness. All the sections were deparaffinized using xylene, dehydrated by gradient ethanol, and then rehydrated with deionized water. Heatmediated antigen retrieval was run by autoclave treatment $\left(120^{\circ} \mathrm{C}\right.$ for $2 \mathrm{~min}$ in $1 \mathrm{mmol} / \mathrm{l}$ EDTA, $\mathrm{pH}$ 8.0) and then followed by cooling at room temperature. Incubation with a polyclonal antibody raised against the $\mathrm{COOH}$ terminus of the human EphA1 receptor (dilution 1:100, ABGENT, San Diego, USA) was performed overnight at $4^{\circ} \mathrm{C}$. After washing with phosphate-buffered saline ( $\mathrm{pH}$ 7.4), the sections were then incubated with secondary antibody (Dako, UK) for $30 \mathrm{~min}$ at room temperature. Color development was performed with 3, 3 -diaminobenzidine. Nuclei were counterstained with hematoxylin. 
Table 1 Correlation between expression of EphA1 transcript and clinicopathologic parameters in 75 colorectal carcinomas

\begin{tabular}{|c|c|c|c|c|c|}
\hline & Case number & $N / T>2$ & N/To.5-2 & $N / T<0.5$ & P-value \\
\hline Overall & 75 & 28 & 17 & 30 & - \\
\hline \multicolumn{6}{|l|}{ Sex } \\
\hline Male & 44 & 17 & 10 & 17 & \multirow[t]{2}{*}{0.952} \\
\hline Female & 31 & 11 & 7 & 13 & \\
\hline \multicolumn{6}{|l|}{ Age (years) } \\
\hline$\leq 55$ & 36 & 13 & 8 & 15 & \multirow[t]{2}{*}{0.96} \\
\hline$>55$ & 39 & 15 & 9 & 15 & \\
\hline \multicolumn{6}{|l|}{ Location } \\
\hline Rectum+sigmoid colon & 57 & 23 & 13 & 21 & \multirow{2}{*}{0.556} \\
\hline Colon & 18 & 5 & 4 & 9 & \\
\hline \multicolumn{6}{|l|}{ Tumor size (cm) } \\
\hline$\leq 5$ & 49 & 18 & 11 & 20 & \multirow[t]{2}{*}{0.98} \\
\hline$>5$ & 26 & 10 & 6 & 10 & \\
\hline \multicolumn{6}{|l|}{ Depth of wall invasion } \\
\hline Mucosa+submucosa & 4 & 3 & 1 & 0 & \multirow[t]{3}{*}{0.278} \\
\hline Muscularis propria & 19 & 7 & 2 & 10 & \\
\hline Subserosa+serosa & 52 & 18 & 14 & 20 & \\
\hline \multicolumn{6}{|l|}{ Tumor differentiation } \\
\hline Well+moderate & 48 & 15 & 13 & 20 & \multirow{2}{*}{0.36} \\
\hline Poor+mucinous & 27 & 13 & 4 & 10 & \\
\hline \multicolumn{6}{|l|}{ Lymph node metastasis } \\
\hline Negative & 46 & 18 & 9 & 19 & \multirow[t]{2}{*}{0.72} \\
\hline Positive & 29 & 10 & 8 & 11 & \\
\hline \multicolumn{6}{|l|}{ Clinical stage (TNM) } \\
\hline I & 20 & 9 & 2 & 9 & \multirow[t]{3}{*}{0.617} \\
\hline II & 25 & 8 & 7 & 10 & \\
\hline $\mathrm{III}+\mathrm{IV}$ & 30 & 11 & 8 & 11 & \\
\hline \multicolumn{6}{|l|}{ Stage (Dukes) } \\
\hline $\mathrm{A}+\mathrm{B}$ & 45 & 17 & 9 & 19 & \multirow[t]{2}{*}{0.78} \\
\hline C & 30 & 11 & 8 & 11 & \\
\hline
\end{tabular}

N/T, normal-tumor; TNM, tumor, node, metastasis.

The immunostaining results were evaluated independently by three pathologists. The different results were unified by consensus. The score of EphA1 expression was made semiquantitatively by assessing the percentage of stained cells and the staining intensity in both tumor tissue and normal mucosa. The percentage of positive cells was rated as follows: 0 score for $0-5 \%, 1$ score for $6-25 \%$, 2 scores for $26-50 \%$, and 3 scores for more than $50 \%$. The staining intensity was rated as follows: 0 score for no staining, 1 score for weak staining, 2 scores for moderate staining, and 3 scores for strong staining. The scores from the percentage and intensity were added to an overall score. The expression of the EphA1 protein in colorectal carcinomas was categorized into downregulation, upregulation, and no difference by comparing the overall score in tumor tissue vs matched normal mucosa.

\section{Methylation-Specific PCR}

Genomic DNA was modified by sodium bisulfite, as described by Clark et al. ${ }^{23}$ Primers were designed to discriminate between methylated and unmethylated alleles after sodium bisulfite treatment. Primer sequences were chosen for the regions containing frequent $\mathrm{CpG}$ near the $3^{\prime}$-end of the primers to provide maximum discrimination between methylated and unmethylated DNA. Aliquots $(2 \mu \mathrm{l})$ were amplified in a 30- $\mu$ l reaction mixture consisting of $1 \times$ buffer $\left(10 \mathrm{mM}\right.$ Tris-HCl, $2.0 \mathrm{mM} \mathrm{MgCl}_{2}, 50 \mathrm{mM}$ $\mathrm{KCl}, \mathrm{pH}$ 8.3), $1 \mathrm{U}$ Takara ExTaq Hotstartaq, $260 \mu \mathrm{M}$ dNTPs, and $0.3 \mu \mathrm{M}$ of the primer sets. The PCR reaction involved $2 \mathrm{~min}$ at $95^{\circ} \mathrm{C}$, then 35 cycles of $94^{\circ} \mathrm{C}$ for $30 \mathrm{~s}, 55^{\circ} \mathrm{C}$ for $30 \mathrm{~s}$, and $72^{\circ} \mathrm{C}$ for $1 \mathrm{~min}$, and finally $10 \mathrm{~min}$ at $72^{\circ} \mathrm{C}$. The methylation-specific primers were $5^{\prime}$-ATTCGGGTTATTGTTTTAGGTT TC-3' (forward) and 5'-GAAAATCGATACCTTC CTTAACG-3' (reverse). The PCR products were 129-bp long. Unmethylation-specific primers were 5'-ATTTGGGTTATTGTTTTAGGTTTTG-3' (forward) and $5^{\prime}$-ACAAAAATCAATACCTTCCTTAACAC- $3^{\prime}$ (reverse). Primer sets for detection of methylated and unmethylated DNA were located at the same sites of genomic sequence (forward primer was located at -35 to -12 from translation start site; reverse primer was located at 71-93; Figure 4). The 
PCR products were 131-bp long. The PCR products were separated on $8 \%$ nondenaturing polyacrylamide gel, followed by ethidium-bromide staining.

\section{Statistical Analysis}

The $\chi^{2}$-test was adopted to determine differences among intergroup variables by use of SPSS 15.0. software (SPSS, Chicago, IL, USA). Kaplan-Meier survival analysis was used to examine the relationship between categorical groups and survival for univariate analysis. A $P$-value $<0.05$ was considered statistically significant.

\section{Results}

Expression of the $\operatorname{EphA1}$ Transcript in Colon Cancer Cell Lines and in Colorectal Carcinomas

RT-PCR was performed to detect the expression of EphA1 transcript in colon cancer cell lines DLD1, HT29, HCT116, SW480, and SW620. EphA1 mRNA was detected in all the colon cancer cell lines (Figure 1). Quantitative real-time RT-PCR was used to detect the expression of EphA1 transcript in 75 fresh specimens of colorectal carcinomas. The ratio of normal-tumor $(\mathrm{N} / \mathrm{T})$ was based on the relative expression level of EphA1 transcript in paired normal mucosa and the tumor tissues of the same patient. The results were classified into three groups according to the ratio of the two: downregulation $(\mathrm{N} / \mathrm{T}>2)$, upregulation $(\mathrm{N} / \mathrm{T}<0.5)$, and no difference (N/T 0.5-2). Down and upregulation of EphA1 transcript were observed in 37\% (28 of 75) and $40 \%$ (30 of 75 ) of the specimens, respectively (Table 1). The association of expression of EphA1 transcript with the sex, age, tumor site, size, depth of wall invasion, differentiation, clinical stage, lymph node metastasis, and Dukes stage were analyzed. No any significant difference between the EphA1 transcript expression and these clinicopathologic parameters was found. The data were summarized in Table 1.

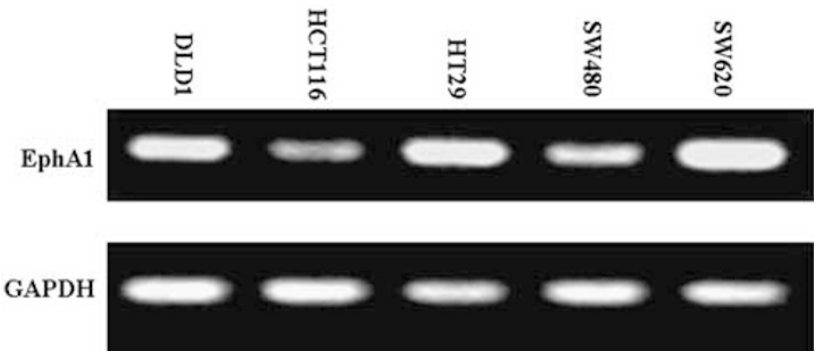

Figure 1 Expression of EphA1 in colon cancer cell lines DLD1, HCT116, HT29, SW480, SW620. Housekeeping gene GAPDH was used as an internal control.

\section{Expression of EphA1 Protein in Colorectal} Carcinomas and Adenomas

The EphA1 protein was detected in most of the normal mucosa cells (Figure 2a (1). The adenoma cells expressed EphA1 protein diffusely (Figure 2a (2). A heterogeneous EphA1-staining pattern between cells was observed in carcinoma tissue sections. The up and downregulations of the EphA1 protein were observed in $31 \%$ (34 of 111) and 54\% (60 of 111) cases of colorectal carcinomas, respectively (Table 2; Figure 2a (3) (4). The immunostaining of EphA1 was observed as particles in cytoplasm or distributed homogenously in cytoplasm (Figure 2b (5) ๔).

\section{The Significance of Reduced Expression of the EphA1 Protein in Colorectal Carcinoma}

The expression of EphA1 protein was significantly related to sex, depth of wall invasion, differentiation, lymphatic metastasis, and clinical stage. The reduced expression of EphA1 was more often occurred in poorly differentiated colorectal carcinomas and mucinous adenocarcinomas than in welland moderately differentiated cases $(P=0.027)$. The patients with reduced EphA1 protein had deeper serosa and subserosa invasiveness than those without EphA1 downregulation $(P=0.003)$. Colorectal carcinomas with reduced EphA1 expression had more advanced tumor stage $(P=0.003)$ and lymph node metastasis $(P=0.034)$. Reduced expression of the EphA1 protein was more often detected in male than in female patients $(P=0.028)$. There was no significant association with other clinicopathologic variables (Table 2).

\section{Reduced EphA1 Protein Expression is Associated with} Poor Survival in Patients with Colorectal Carcinoma

We examined the association of EphA1 protein expression with clinical outcome. The KaplanMeier survival analysis showed patients with reduced EphA1 expression had shorter survival than those with high EphA1 expression (log-rank test, $P=0.059$; Figure 3 (1). Reduced EphA1 expression in patients over 55 years or with rectal cancers and sigmoid colon cancers is associated with a poor overall survival $(P=0.034$ and 0.015 , respectively; Figure 3 (2) (3).

\section{Detection of Methylated EphA1 DNA in Colon Cancer Cell Lines}

Five colon cancer cell lines DLD1, HCT116, HT29, SW480, and SW620 were checked for methylation status at promoter-associated region of EphA1 by methylation-specific PCR. Methylated DNA of $E p h A 1$ was detected in all five tested colon cancer cell lines (Figure 4). 


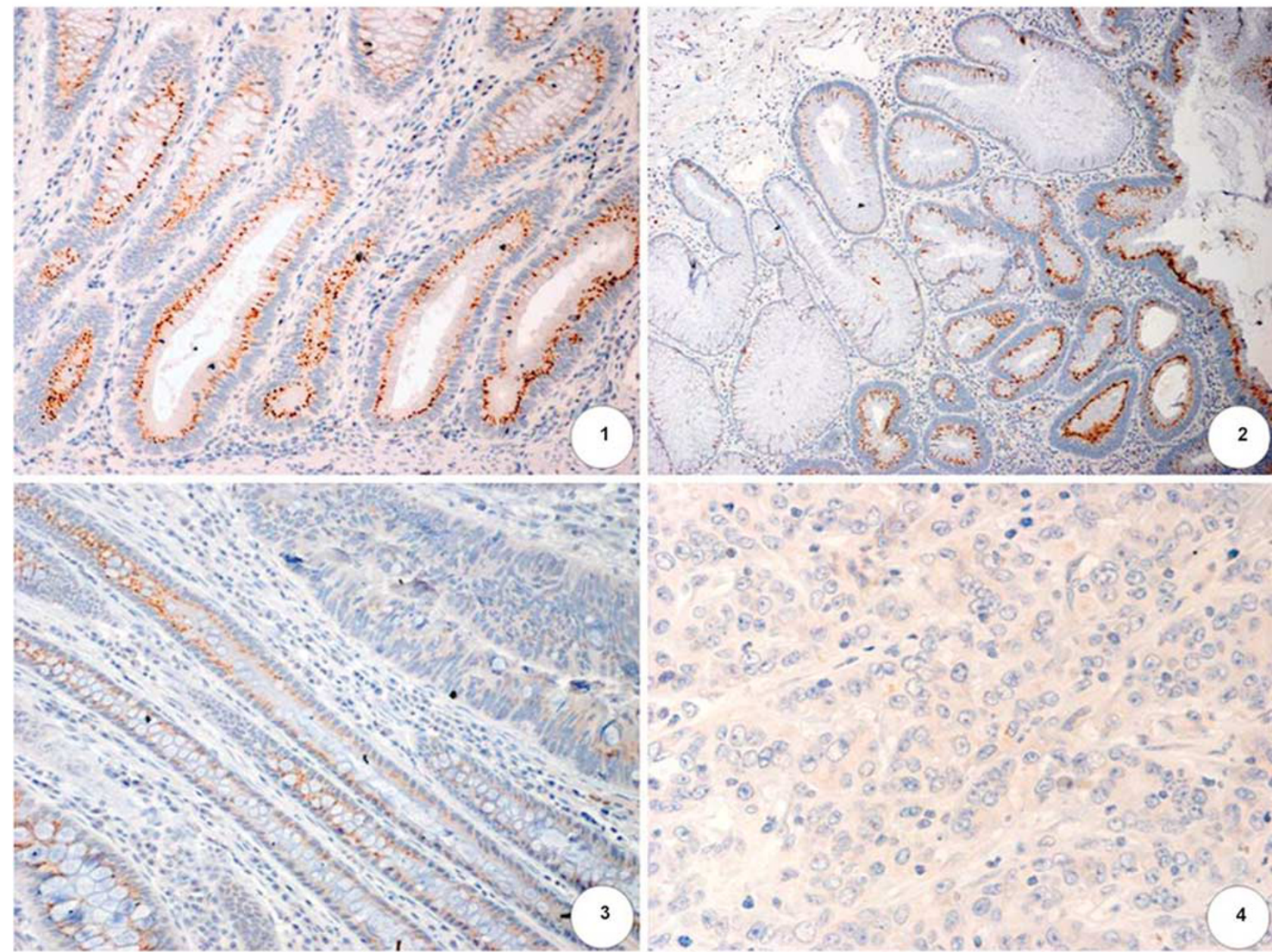

b

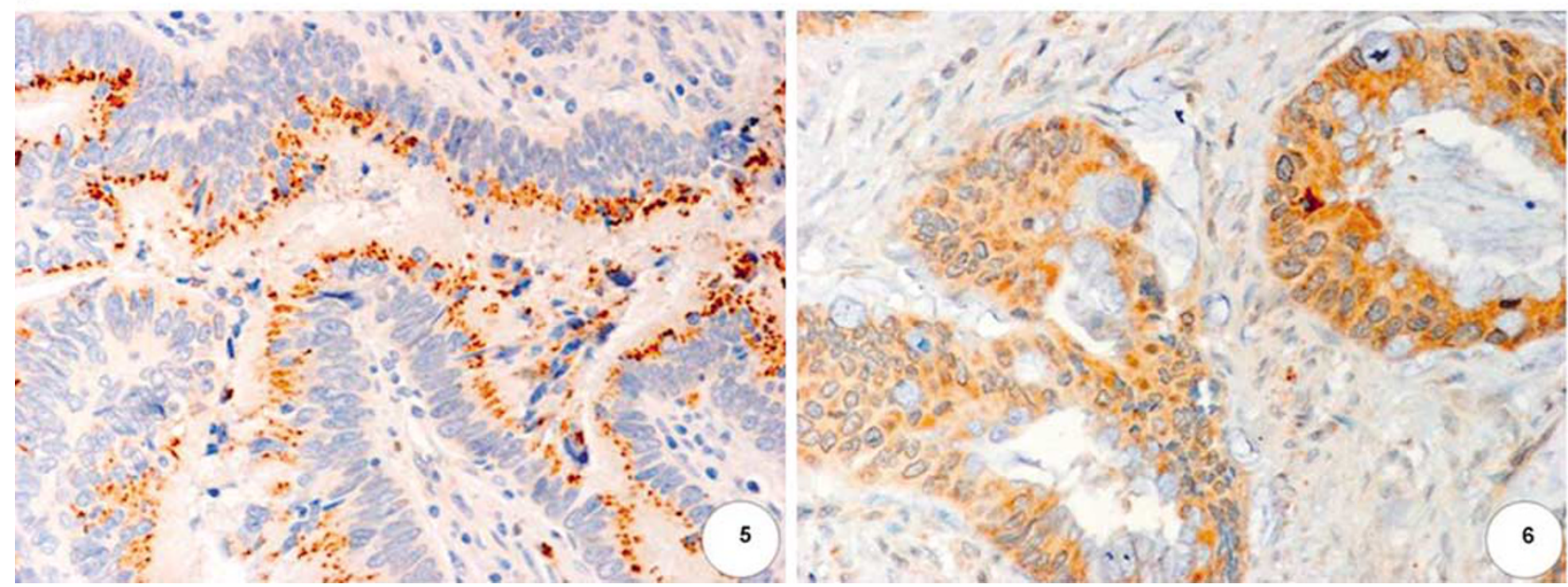

Figure 2 (a) Immunohistochemical staining of EphA1 in colorectal carcinomas. (1) The expression of EphA1 in normal mucosa (EnVision, original magnification $\times 200$ ). (2) Upregulation of $E p h A 1$ in adenoma cells (right lower) compared with normal mucosas (left upper; EnVision, original magnification $\times 100$ ). (3) Downregulation of EphA1 in carcinoma cells (right upper) compared with normal mucosas (left lower; EnVision, original magnification $\times 200$ ). (4) Lost expression of EphA1 in poorly differentiated carcinoma cells (EnVision, original magnification $\times 400$ ). (b) (5) Strong immunoreactivity was detected in moderately differentiated carcinoma cells. The subcellular localization of EphA1 protein revealed the accentuation of golgiosome (EnVision, original magnification $\times 400$ ). (6) EphA1 protein was expressed homogeneously in cytoplasm (EnVision, original magnification $\times 400$ ). 
Table 2 Correlation between EphA1 protein expression and clinicopathologic parameters in 111 colorectal carcinomas

\begin{tabular}{|c|c|c|c|c|c|}
\hline & Case number & Downregulation & No difference & Upregulation & P-value \\
\hline Overall & 111 & 60 & 17 & 34 & - \\
\hline \multicolumn{6}{|l|}{ Sex } \\
\hline Male & 66 & 37 & 14 & 15 & \multirow{2}{*}{0.028} \\
\hline Female & 45 & 23 & 3 & 19 & \\
\hline \multicolumn{6}{|l|}{ Age (years) } \\
\hline$\leq 55$ & 49 & 31 & 8 & 10 & \multirow[t]{2}{*}{0.109} \\
\hline$>55$ & 62 & 29 & 9 & 24 & \\
\hline \multicolumn{6}{|l|}{ Location } \\
\hline Rectum+sigmoid colon & 81 & 40 & 12 & 29 & \multirow[t]{2}{*}{0.144} \\
\hline Colon & 30 & 20 & 5 & 5 & \\
\hline \multicolumn{6}{|l|}{ Tumor size $(\mathrm{cm})$} \\
\hline$\leq 5$ & 80 & 40 & 14 & 26 & \multirow[t]{2}{*}{0.352} \\
\hline$>5$ & 31 & 20 & 3 & 8 & \\
\hline \multicolumn{6}{|l|}{ Depth of wall invasion } \\
\hline Mucosa+submucosa & 10 & 3 & 3 & 4 & \multirow[t]{3}{*}{0.003} \\
\hline Muscularis propria & 24 & 7 & 3 & 14 & \\
\hline Subserosa+serosa & 77 & 50 & 11 & 16 & \\
\hline \multicolumn{6}{|l|}{ Tumor differentiation } \\
\hline Well+moderate & 80 & 37 & 15 & 28 & \multirow[t]{2}{*}{0.027} \\
\hline Poor+mucinous & 31 & 23 & 2 & 6 & \\
\hline \multicolumn{6}{|l|}{ Lymphatic metastases } \\
\hline Negative & 66 & 29 & 12 & 25 & \multirow[t]{2}{*}{0.034} \\
\hline Positive & 45 & 31 & 5 & 9 & \\
\hline \multicolumn{6}{|l|}{ Clinical stage (TNM) } \\
\hline I & 28 & 7 & 5 & 16 & \multirow[t]{3}{*}{0.003} \\
\hline II & 37 & 22 & 7 & 8 & \\
\hline $\mathrm{III}+\mathrm{IV}$ & 46 & 31 & 5 & 10 & \\
\hline \multicolumn{6}{|l|}{ Stage (Dukes) } \\
\hline $\mathrm{A}+\mathrm{B}$ & 65 & 29 & 12 & 24 & \multirow[t]{2}{*}{0.06} \\
\hline C & 46 & 31 & 5 & 10 & \\
\hline
\end{tabular}

N/T, normal-tumor; TNM, tumor, node, metastasis.

\section{Discussion}

The Eph gene family is the largest subfamily of receptor tyrosine kinase including at least 16 receptors and 9 ligands. The role of Eph family in developing processes has been well documented. The interaction of Eph receptors and their ligands controls the cells repulsion and movement during tissue patterning in embryonic development. However, the roles of Eph and Ephrin proteins in tumorigenesis are not clearly established. The Eph family was initially known as a putative oncogene based on their overexpression in certain types of human cancers. The EphA2 receptor is overexpressed in colorectal, ${ }^{24}$ gastric,${ }^{25}$ ovarian, ${ }^{11}$ and esophageal squamous-cell carcinoma. ${ }^{26}$ The EphA4 receptor is overexpressed in pancreatic ductal adenocarcinoma, ${ }^{27}$ and Ephrin $B 1$ is overexpressed in ovarian carcinoma. ${ }^{28}$ More recently, increasing data have shown that some members of Eph receptors and Ephrin ligands have roles of tumor suppressor. A representative example is that certain
EphB subfamily proteins, including EphB2, EphB4, suppress colorectal cancer progression through Wnt signal pathway. ${ }^{9,10,29}$

The EphA1 receptor is widely expressed in human normal tissues. However, its expression levels in different types of human tumors are greatly diverse, and its role in tumorigenesis is still very vague. In the present study, we described the expression of the EphA1 transcript and protein in colorectal carcinomas and analyzed the association of expression of EphA1 with clinicopathologic parameters.

The EphA1 transcript was detected in all five colon cancer cell lines DLD1, HCT116, HT29, SW480, and SW620 by RT-PCR (Figure 1). The expression levels of EphA1 mRNA in five colon cancer cell lines were different. There is a CG-rich region around EphA1 translation start site (Figure 4a), the methylation, and unmethylationspecific primer sets were designed by using web software MethPrimer (http://www.urogene.org// methprimer/). Methylated and unmethylated DNA 

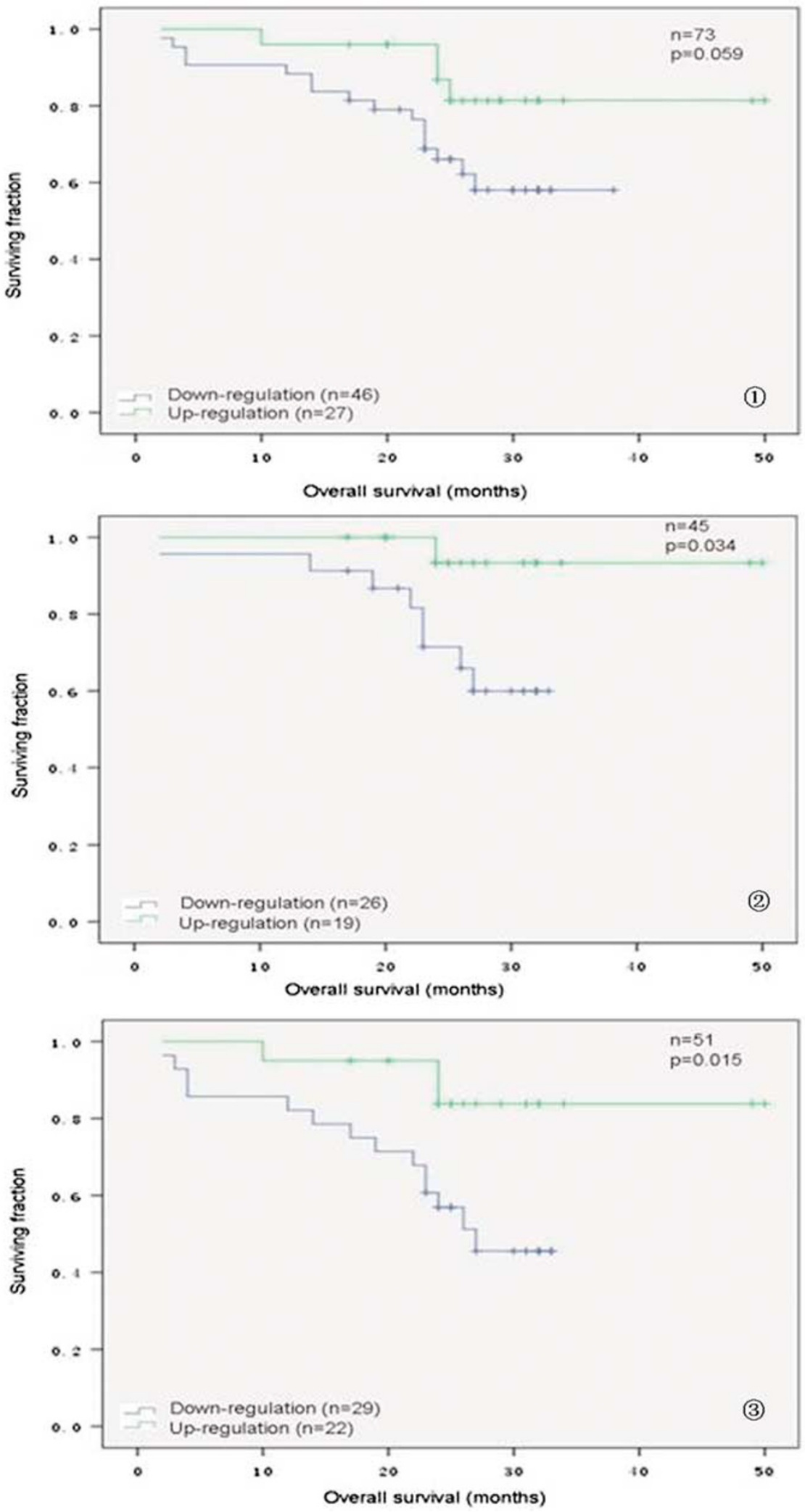

Figure 3 (1) Kaplan-Meier plots of overall survival showed patients with EphA1 downregulation had a shorter survival than those with EphA1 upregulation $(P=0.059)$. (2) (3) Kaplan-Meier plots of overall survival showed reduced EphA1 expression in patients over 55 years or with rectal cancers and sigmoid colon cancers is associated with a poor overall survival $(P=0.034$ and 0.015 , respectively). 

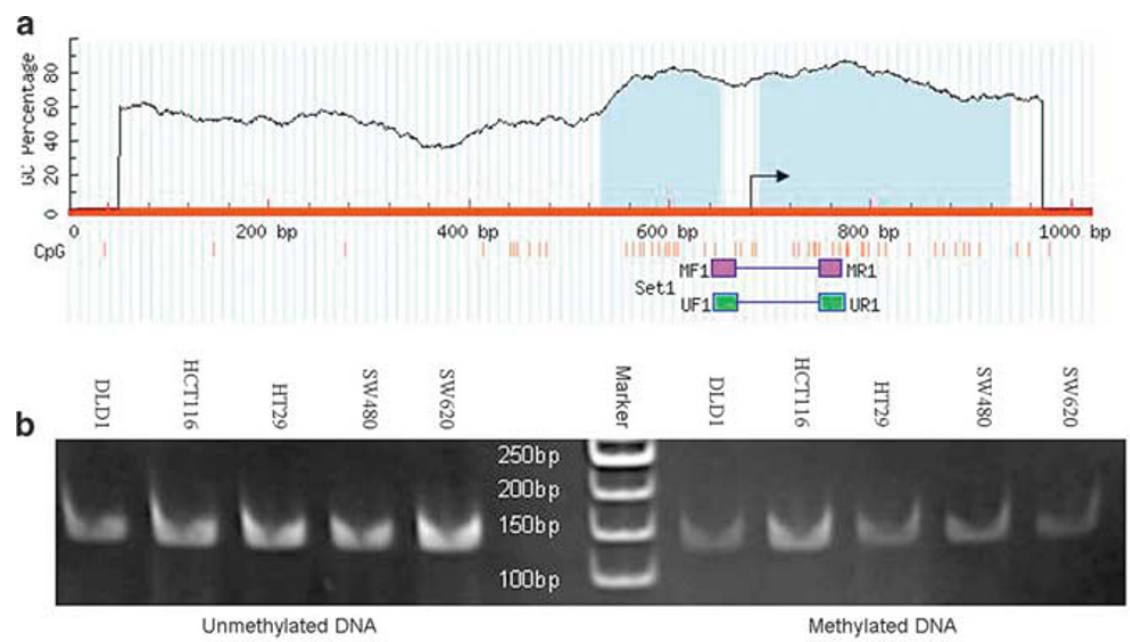

Figure 4 (a) Schematic show of the promoter-associated CpG island in EphA1 and the location of PCR primer sets for specific detection of methylation and unmethylation EphA1 DNA. The arrow showed the translation start site of EphA1. (b) Methylated and unmethylated DNAs of EphA1 were detected in colon cancer cell lines.

of EphA1 was detected in all tested five colon cancer cell lines (Figure 4b). To explore the methylation status of the promoter-associated CpG island of EphA1 in tissue DNA of colorectal carcinomas and the association of the methylation with clinicopathologic parameters will be our next project.

The expression of EphA1 transcript was downregulated in $37 \%$ and upregulated in $40 \%$ tested samples. No significant relation between the EphA1 transcript expression and clinicopathologic parameters was found (Table 1). The EphA1 protein was detected in most of the normal mucosa cells and diffusely expressed in adenoma cells (Figure 2). However, in the colorectal carcinomas, the EphA1 expression was showed heterogeneity in carcinoma cells both of intra- and inter-samples. Our data suggest that EphA1 protein was partly lost in the transition from adenomas to adenocarcinomas. Reduced expression of EphA1 protein occurred more often in male patients $(P=0.028)$ and in patients with poor differentiation $(P=0.027)$, greater depth of wall invasion $(P=0.003)$, lymph node metastasis $(P=0.034)$, and advanced tumor stage $(P=0.003)$. These data show that EphA1 may be involved in the progression of colorectal carcinomas. Although EphA1 has a closer homologous sequence and more similar structure to EphA2 than any other Eph receptor, ${ }^{30}$ our results show that there are great different features between them in terms of protein expression and its relation to clinicopathologic parameters in colorectal carcinomas. EphA2 expression is present at the cytomembrane of the normal colorectal epithelium. However, EphA2 immunoreactivity in colorectal carcinoma cells was diffusely distributed throughout the cytoplasm, with little staining of the cytomembrane. ${ }^{24}$ In this study, different subcellular localization of EphA1 was found. In normal mucosa gland and adenoma cells, the immunostaining of EphA1 was showed dense brown particles in the Golgi's body. This staining pattern was only showed in parts of well-differentiated carcinoma cells. In poorly differentiated carcinoma and parts of well-differentiated carcinoma cells, the EphA1 was diffusely stained in cytoplasm. The staining pattern of EphA1 in skin ulcers was also altered, in which EphA1 was expressed in keratinocytes adjacent to the rim of the ulcer with an intense cytoplasmic staining, but with a membranous staining in those distant from the rim of the same ulcer. ${ }^{22}$ The mechanism for this altered EphA1 immunostaining pattern is unknown. In addition, overexpression of EphA2 is associated with metastasis and stage of the cancer. ${ }^{24}$ However, in this study, reduced expression of EphA1 occurred more often in patients with advanced tumor stage and lymph node metastasis. Our data suggest that EphA1 and EphA2 play different roles in the progression of colorectal carcinomas.

The expression of EphA1 protein was not completely consistent with the transcript expression in 75 samples, in which only $35 \%$ (26 of 75 ) showed consistency. This pattern was also reported on EphB4 expression in breast carcinomas, ${ }^{31}$ EphA2 expression in bladder carcinomas, ${ }^{32}$ and EphA7 expression in hepatocellular carcinomas. ${ }^{18}$ The post-transcription regulation mechanisms interpreted EphB4 and EphA2 differential expression between protein and transcript. Upregulation of EphA7 mRNA in hepatocellular carcinomas may be attributable to higher vascularization in the investigated tumor, resulting in intercellulalr crosscontaminations. In the present study, EphA1 staining was not observed in stromal cells, vascular endothelial cells, or lymphocytes; we postulate that post-transcription, post-translation regulation mechanisms, or quick degradation of unstable EphA1 protein are the reasons of inconsistent expression of EphA1 mRNA and protein. 
Follow-up information was available in 73 patients with a follow-up duration of 2-50 months (median time: 25 months), including 46 cases with reduced EphA1 expression and 27 cases with EphA1 upregulation. The overall survival rate in patients with EphA1 downregulation was shorter than that in patients with EphA1 upregulation (logrank test, $P=0.059$ ). Reduced EphA1 expression in patients over 55 years or with rectal cancers and sigmoid colon cancers is associated with a poor overall survival ( $P=0.034$ and 0.015 , respectively). The protective roles of EphA1 protein in aged colorectal patients and patients with rectal cancers and sigmoid colon cancers are more obvious.

In summary, reduced expression of the EphA1 protein in colorectal carcinomas is related to invasiveness, differentiation, metastasis, stage, and prognosis. Our data implicate that EphA1 receptor may play different roles in the different stage of progression of colorectal carcinomas.

\section{Acknowledgements}

We thank Benkun Ma and Zhenfeng Lu for help with RT-PCR and the immunohistochemical staining. This work was in part supported by National Basic Research Priorities Program 973 Project (2006, CB 705707) from the Ministry of Science and Technology of China, China Nanjing medicine science and technology research project (no. 06Z37).

\section{References}

1 Jemal A, Siegel R, Ward E, et al. Cancer statistics, 2007. CA Cancer J Clin 2007;57:43-66.

2 Unified nomenclature for Eph family receptors and their ligands, the ephrins. Eph Nomenclature Committee. Cell 1997;90:403-404.

3 Martinez A, Soriano E. Functions of ephrin/Eph interactions in the development of the nervous system: emphasis on the hippocampal system. Brain Res Brain Res Rev 2005;49:211-226.

4 Kadison SR, Makinen T, Klein R, et al. EphB receptors and ephrin-B3 regulate axon guidance at the ventral midline of the embryonic mouse spinal cord. J Neurosci 2006;26:8909-8914.

5 Jevince AR, Kadison SR, Pittman AJ, et al. Distribution of EphB receptors and ephrin-B1 in the developing vertebrate spinal cord. J Comp Neurol 2006;497: 734-750.

6 Gerety SS, Anderson DJ. Cardiovascular ephrinB2 function is essential for embryonic angiogenesis. Development 2002;129:1397-1410.

7 Zhang J, Hughes S. Role of the ephrin and Eph receptor tyrosine kinase families in angiogenesis and development of the cardiovascular system. J Pathol 2006;208:453-461.

8 Tanaka M, Kamata R, Takigahira M, et al. Phosphorylation of ephrin-B1 regulates dissemination of gastric scirrhous carcinoma. Am J Pathol 2007;171:68-78.
9 Davalos V, Dopeso H, Castano J, et al. EPHB4 and survival of colorectal cancer patients. Cancer Res 2006;66:8943-8948.

10 Batlle E, Bacani J, Begthel H, et al. EphB receptor activity suppresses colorectal cancer progression. Nature 2005;435:1126-1130.

11 Thaker PH, Deavers M, Celestino J, et al. EphA2 expression is associated with aggressive features in ovarian carcinoma. Clin Cancer Res 2004;10: 5145-5150.

12 Fox BP, Kandpal RP. Invasiveness of breast carcinoma cells and transcript profile: Eph receptors and ephrin ligands as molecular markers of potential diagnostic and prognostic application. Biochem Biophys Res Commun 2004;318:882-892.

13 Potla L, Boghaert ER, Armellino D, et al. Reduced expression of EphrinA1 (EFNA1) inhibits three-dimensional growth of HT29 colon carcinoma cells. Cancer Lett 2002;175:187-195.

14 Brantley DM, Cheng N, Thompson EJ, et al. Soluble Eph A receptors inhibit tumor angiogenesis and progression in vivo. Oncogene 2002;21:7011-7026.

15 Wang J, Kataoka H, Suzuki M, et al. Downregulation of EphA7 by hypermethylation in colorectal cancer. Oncogene 2005;24:5637-5647.

16 Wang J, Li G, Ma H, et al. Differential expression of EphA7 receptor tyrosine kinase in gastric carcinoma. Hum Pathol 2007.

17 Hirai H, Maru Y, Hagiwara K, et al. A novel putative tyrosine kinase receptor encoded by the eph gene. Science 1987;238:1717-1720.

18 Hafner C, Schmitz G, Meyer S, et al. Differential gene expression of Eph receptors and ephrins in benign human tissues and cancers. Clin Chem 2004;50: 490-499.

19 Herath NI, Spanevello MD, Sabesan S, et al. Overexpression of Eph and ephrin genes in advanced ovarian cancer: ephrin gene expression correlates with shortened survival. BMC Cancer 2006;6:144.

20 Lin HS, Berry GJ, Fee Jr WE, et al. Identification of tyrosine kinases overexpressed in head and neck cancer. Arch Otolaryngol Head Neck Surg 2004;130:311-316.

21 Fox BP, Tabone CJ, Kandpal RP. Potential clinical relevance of Eph receptors and ephrin ligands expressed in prostate carcinoma cell lines. Biochem Biophys Res Commun 2006;342:1263-1272.

22 Hafner C, Becker B, Landthaler M, et al. Expression profile of Eph receptors and ephrin ligands in human skin and downregulation of EphA1 in nonmelanoma skin cancer. Mod Pathol 2006;19:1369-1377.

23 Clark SJ, Harrison J, Paul CL, et al. High sensitivity mapping of methylated cytosines. Nucleic Acids Res 1994;22:2990-2997.

24 Saito T, Masuda N, Miyazaki T, et al. Expression of EphA2 and E-cadherin in colorectal cancer: correlation with cancer metastasis. Oncol Rep 2004;11: 605-611.

25 Nakamura R, Kataoka H, Sato N, et al. EPHA2/EFNA1 expression in human gastric cancer. Cancer Sci 2005;96:42-47.

26 Miyazaki T, Kato H, Fukuchi M, et al. EphA2 overexpression correlates with poor prognosis in esophageal squamous cell carcinoma. Int $\mathrm{J}$ Cancer 2003;103:657-663.

27 Iiizumi M, Hosokawa M, Takehara A, et al. EphA4 receptor, overexpressed in pancreatic ductal adenocar- 
cinoma, promotes cancer cell growth. Cancer Sci 2006;97:1211-1216.

28 Castellvi J, Garcia A, de la Torre J, et al. Ephrin B expression in epithelial ovarian neoplasms correlates with tumor differentiation and angiogenesis. Hum Pathol 2006;37:883-889.

29 Clevers H, Batlle E. EphB/EphrinB receptors and Wnt signaling in colorectal cancer. Cancer Res 2006;66:2-5.
30 Drescher U. Eph family functions from an evolutionary perspective. Curr Opin Genet Dev 2002;12:397-402.

$31 \mathrm{Wu}$ Q, Suo Z, Risberg B, et al. Expression of Ephb2 and Ephb4 in breast carcinoma. Pathol Oncol Res 2004;10:26-33.

32 Abraham S, Knapp DW, Cheng L, et al. Expression of EphA2 and Ephrin A-1 in carcinoma of the urinary bladder. Clin Cancer Res 2006;12:353-360. 